\title{
Hope for Haiti?
}

\author{
Hans Veeken
}

Haiti, one of the world's five poorest nations, gets international attention because of the number of refugees who leave by boat in search of a better future. The 80000 inhabitants of Ile de la Gonave are neglected, even in Haiti-there is no government medical post, and facilities in the health posts run by missions are minimal. Typhoid and cholera epidemics threaten the island. Médecins Sans Frontières plans to send staff and supplies and train local health workers.

"Don't I fool around with the people?" the priest asked me. "In our school we teach the children how to read and write, but when they are able, what's next? On the whole island you cannot buy a newspaper, book, or pencil, nothing." I visited Haiti on an exploratory mission to assess if Médecins Sans Frontières could offer support. As we sat on the verandah in the moonlight, the priest, smoking Havana-type cigars, explained to me the difficult situation of Ile de la Gonave. During our conversation villagers passed by continuously for his advice. That afternoon, travelling in one of the 10 Land-rovers on the island, I had seen the school he referred to: the "building" was transparent, four poles and some netting functioning as a wall, offering a nice view of the violet uniforms of the pupils contrasting with the black netting. Ile de la Gonave is, even in Haiti, a forgotten place. The island has 80000 inhabitants but there is not a single government health post.

The priest, who had worked for over 30 years on the island, told me with disillusion: "It is worse than ever." The official figures confirm his statement. Life expectancy is $\mathbf{5 4}$ years, the fertility rate is 6.4 children per woman, $75 \%$ of the population is illiterate, $60 \%$ is unemployed, and the average annual income per capita is a mere US $\$ 250$. Haiti is one of the five poorest countries in the world. The population is entirely

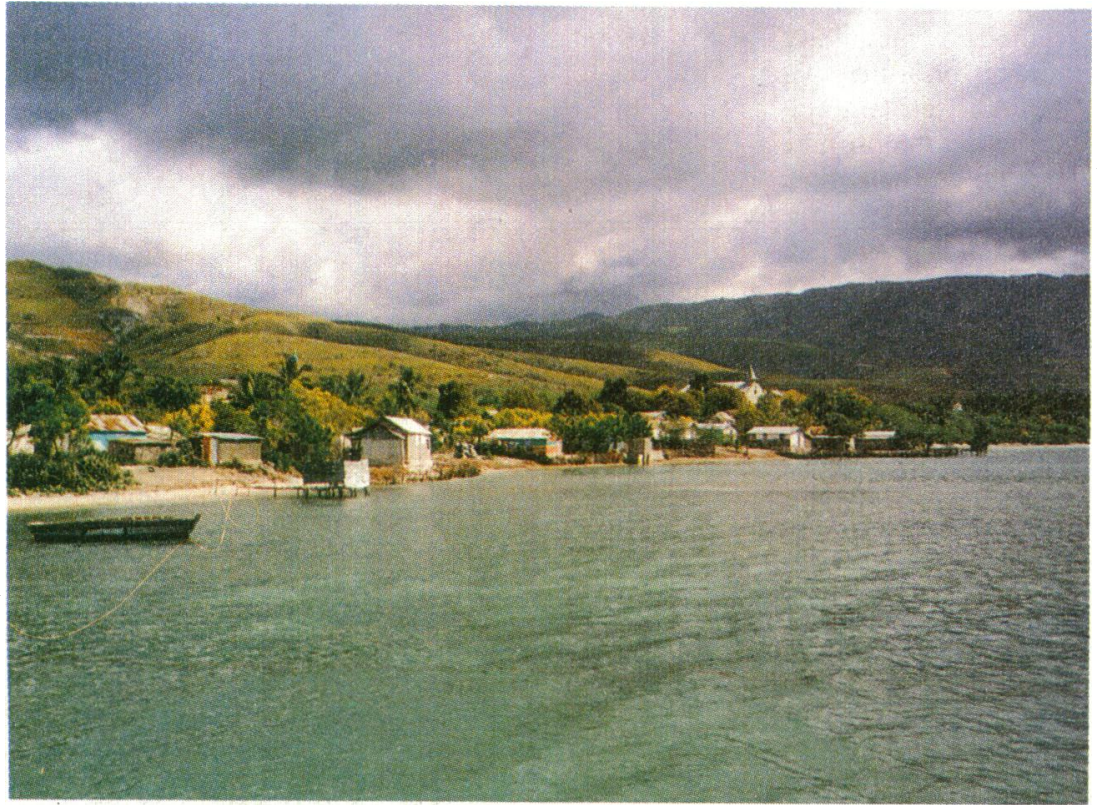

No tropical paradise-Ile de la Gonave, Haiti. Patients are transferred to hospital by boat, no joke during heavy weather black-it is Africa in the Caribbean, and only two hours' flying time from Florida. A small elite of mulattos is ruling the country. The first democratically chosen president, the priest Aristide, became too powerful and was ousted by the military.

\section{To the island}

Ile de la Gonave, where the priest runs his parish, is easily visible from the capital, Port au Prince. Nobody in town, however, could give me any sensible information on the current situation on the island. Nobody had been there, but everybody had a horror story to discourage me. "Take along drinking water because there is typhoid," was the advice given to me as I left for the island. The "tap-tap," a small van meant for public transport, wriggled through the outskirts of Port au Prince. As usual, we first had to refuel. At the gas station I noticed, instead of the normal pool of oil, a pool of blood on the ground. To my astonishment I discovered in the bushes at the side a corpse, beheaded. "Military," said my companion. The facts of the case did not seem to bother anybody; they are used to terror.

On the beach at Montrouis three sailing boats were waiting to sail, their bright red colour contrasting with the deep blue waters. Everybody addressed me in Creole, and suddenly I found myself sitting on the neck of a Haitian; he carried "le blanc" on his shoulders dry towards the boat. Luckily all passengers got this treat. Sailing with this ship to Miami is not a tempting prospect, but thousands of Haitians try to escape their country this way. Hundreds die on the way-they drown, unable to swim. The stories are horrible: old people are thrown in the sea when the weather conditions get too harsh.

\section{Only one doctor}

In next to no time you could assess that the island is hopelessly neglected. There is no electricity and no telephone, and the road turns out to be a nightmare. It took us two hours to travel $28 \mathrm{~km}$ to reach a health post run by a mission. The people travel by foot or by boat. "You are the first doctor that has visited our dispensary for years," the auxiliary nurse told me when we eventually arrived. "Our nurses work hard and they are competent, but everybody needs some support, don't they?" "On the whole island there is only one doctor, but she is too busy to leave the hospital," the priest added. The health post had a bare minimum of equipment, but it was clean and fully in use. There was no fridge, no light, no running water, and no instruments to pull teeth. A patient who needs referral is transported by sailing boat-no joke during heavy weather. "On the whole island there are four of these health posts, all run by different denominations," the priest explained. "One of them, run by the Protestant church, is closed; the expatriate personnel were withdrawn because of the embargo, imposed in 1991. They took the key with them."

We visited another post in the interior of the island, in the mountains. The people seemed a bit better off, there was more drinking water, and it was cooler. Here too we found a lack of medical supplies. A patient lay 
bathed in sweat on a stretcher in a corner. "Typhoid," a nurse assured me. "We already referred three cases." Apparently there are no possibilities of verifying the diagnosis, nor of sorting out the source; it was just a matter of waiting with resignation until the next patient arrived. It did not surprise me that there was typhoid on the island. Latrines are very few, the soil is rock hard, and drinking water is rationed. On the little square in front of the mission, people queued at the well in the middle of the night to fill their buckets. Typhoid is not the only epidemic that threatens the island. What will happen if cholera gets a foothold? This is likely to happen because cholera has spread rapidly all over Latin America, though so far it has spared Haiti.

\section{Missions and churches}

The health facilities on the island are insufficient for 80000 inhabitants. The one and only hospital-40 beds, and run by American missionaries-holds its own with a hospital in rural Africa. The sisters try to make ends meet. "The $x$ ray is out of order and the laboratory deteriorates," the doctor told me, sighing. "We did have a good laboratory technician but he left for the States. He broke a new person in, and this one is training in his turn an assistant." She made a gentle undulating downward movement with both hands. "I cannot do everything myself, can I? I would like to train more nurses and organise an outreach programme - the people on the other side of the island never see a doctor."

The cooperation between the different denominations is formal and seems a bit cool. "You know," the priest tells me, "the Protestants are so strict. Before the outpatient department starts the people are supposed to pray; only then do they receive a serial number. One prays in the church and not in the hospital, what do you think? But to be honest, I believe we see it more as a problem than do the
Haitians. They do not so much mind praying, and it is the same to them to which god. If they do not have time, they send their cousin to pray and collect the number." Another missionary told me, however, that it is unbelievable how someone who lives in sin (the priest is a heavy smoker) can guide the people along the correct path.

\section{A medical mission}

Back in Port au Prince everybody wanted to get hold of the hot news of the situation on the island. It is remarkable that so few people from Port au Prince have visited the island themselves-the island is easily visible from the harbour. The situation is not too complicated: one doctor for 80000 inhabitants is very little, and there is a great lack of drugs and supplies.

Médecins Sans Frontières could well support the island with both staff and supplies and set up outreach activities. Before it is too late, action is needed to deal with the typhoid epidemic and a contingency plan in case of a cholera epidemic has to be prepared. Training of the local health workers will be an important component in combating these two diseases. Malaria and tuberculosis are both killer diseases on the islandit will be necessary to train microscopists to diagnose both diseases correctly.

The other organisations are glad that a Médecins Sans Frontières team will be arriving. The extra input for the island is appreciated. However, there is little cooperation with the government, which came to power with a coup and therefore is not recognised by most political parties in Haiti. Haiti gets international attention because of the number of Haitians who try to reach the United States by boat in search of a better future. This will make it easier to find funding for a programme, especially as many refugees come from Ile de la Gonave.

(Accepted 21 May 1993)

\title{
Medical practice guidelines: lessons from the United States
}

\author{
Andrew Farmer
}

Clinical guidelines, or protocols, have been devised by many different groups, often with differing aims. Some aim to reduce variations in care by using guidelines, while others seek to improve outcomes. Guidelines have long been used in the United States to try to control the behaviour of the medical profession-and the cost of health care. The "effectiveness initiative," run by the Agency for Health Care Policy and Research spawned much activity among other groups, including the American Medical Association and the American College of Physicians. The experience of the Americans in analysing data to gauge effectiveness and then in disseminating good practice may help British moves in this direction. In particular, it is often hard to get guidelines adopted in practice; doctors have to be exposed to the same message in different forms.

Health Services Research Unit, Department of Public Health and Primary Care, University of Oxford, Radcliffe Infirmary, Oxford OX2 6HE

Andrew Farmer, general practice research fellow

BMF 1993;307:313-7 a recommendation for patient management that identifies one or more strategies for treatment. Traditionally practice guidelines are viewed as a mechanism for offering advice to doctors about their clinical management. Guidelines were originally intended for junior doctors or physician assistants, but the idea has been developed by different groups. The ultimate aim, of course, is to inform doctors of "the right thing to do." However, the "right thing" ultimately depends on judgments based on personal values. Different groups have different agendas. Some want to control costs. Others want to reduce the variations between doctors in an attempt to manage care. Others want to improve the outcomes of medical care by basing it more firmly on the results of research data. The user-whether doctor, patient, or manager-needs to understand something about the objectives of the guideline, and the method of developing it, to judge whether the final balance of opinions is fair and reasonable.

This report looks at the development of practice guidelines in the United States and draws parallels with the current situation in Britain. Where do guidelines fit in with the current interest in research about the outcomes of medical care? How are practice guidelines being used? What are their strengths and weaknesses, 